\title{
News from the CIS Executive Committee
}

\author{
Sergio D. Rosenzweig
}

Received: 15 December 2013 / Accepted: 20 December 2013 / Published online: 9 January 2014

(C) Springer Science+Business Media New York (outside the USA) 2014

Dear JoCI Readers and Clinical Immunologists,

We are pleased to provide you with some exciting updates on two initiatives the leadership and staff of CIS have implemented.

The CIS continues to expand and cultivate its international relationships. During the last 6 months partnership programs with related regional organizations in Africa (African Society for Immunodeficiencies ASID-), Europe (European Society for Immunodeficiencies -ESID- and J-Project), and Latin America (with the Latin American Society for Immunodeficiencies LASID-) have been established. Under these new agreements, full CIS membership has been offered to all our partnering society colleagues at a reduced fee of $\$ 50$ per year. This initiative will scientifically enrich our society and multiply the outreach of our message into the Clinical Immunology/Primary Immunodeficiency community. New agreements with these and other scientific societies that have shared interests with the CIS are being explored. For example, CIS has agreed with ESID and LASID to publish the abstracts from their biennial conferences in the JoCI, and we are working with the other partner societies to reach similar deals.

S. D. Rosenzweig $(\bowtie)$

NIH, Rockville, MD, USA

e-mail: srosenzweig@cc.nih.gov
We also are proud to inform you that CIS now offers complimentary full membership to all Clinical Immunology Trainees worldwide (http://www.clinimmsoc.org/ membership/eligibility-requirements). Fellows will only have to attest to their enrollment in a Clinical Immunology training program, and then will be granted complimentary full CIS membership for the duration of their training (maximum 3 years). CIS is committed to fostering the development of Fellows and Trainees, feeling very strongly that membership in CIS is vital to an immunologist's career development; therefore, membership will be encouraged and accessible to all trainees in Clinical Immunology.

We invite you, your trainees and all members of the Clinical Immunology community to visit the CIS website (http:// www.clinimmsoc.org/) for details on partner societies, for instructions about how to become a CIS member, and for the many educational tools on his site.

We also want to remind you to register for the 2014 CIS Annual Meeting: Primary Immune Deficiency Diseases North American Conference on April 10-13, 2014 in Baltimore, Maryland.

Finally, please encourage your colleagues and friends to submit their finest research articles for publication in the Journal of Clinical Immunology, the official journal of the CIS (http://www.clinimmsoc.org/meetings/annual-meeting/2014annual-meeting).

Sincerely,

CIS Executive Committee 